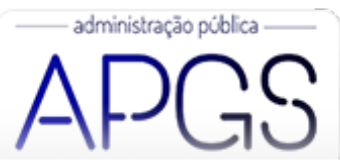

Administração Pública e Gestão Social ISSN: 2175-5787

apgs@ufv.br

Universidade Federal de Viçosa

Brasil

\title{
Contabilidade aplicada ao Setor Público: Um Estudo Sobre o Reconhecimento da Depreciação na Contabilidade dos Estados Brasileiros
}

Moreira Carvalho Andrade, Maria Elisabeth; da Silva Suzart, Janilson Antonio

Contabilidade aplicada ao Setor Público: Um Estudo Sobre o Reconhecimento da Depreciação na Contabilidade dos Estados Brasileiros

Administração Pública e Gestão Social, vol. 11, núm. 2, 2019

Universidade Federal de Viçosa, Brasil

Disponível em: http://www.redalyc.org/articulo.oa?id=351558326002

Esta obra está bajo una Licencia Creative Commons Atribución-NoComercial-SinDerivar 3.0 Internacional. 


\title{
Contabilidade aplicada ao Setor Público: Um Estudo Sobre o Reconhecimento da Depreciação na Contabilidade dos Estados Brasileiros
}

\author{
Governmental Accounting: A Study of the Recognition of Depreciation in the Brazilian States Accounts \\ Contabilidad Gubernamental: El estudio del reconocimiento de la depreciación en las cuentas públicas
}

\author{
Maria Elisabeth Moreira Carvalho Andrade \\ Universidade Federal de Uberlândia, Brasil \\ maria.elisabeth@ufu.br
}

Redalyc: http://www.redalyc.org/articulo.oa?

\author{
Janilson Antonio da Silva Suzart \\ Universidade de São Paulo, Brasil \\ jassuzart@yahoo.com.br
} $\mathrm{id}=351558326002$

Recepção: 07 Novembro 2016

Aprovação: 08 Fevereiro 2018

Publicado: 01 Abril 2019

\section{Resumo:}

O objetivo deste artigo foi comparar os efeitos do reconhecimento da depreciação nos entes subnacionais brasileiros, no período entre 2003 e 2014. Assim, inicialmente, buscou-se coletar dados relacionados à variação da depreciação, do imobilizado e da variação patrimonial diminutiva de todos os entes subnacionais (Estados e o Distrito Federal, mais especificamente), na base de dados do FINBRA - Finanças do Brasil. A amostra final ficou composta por treze entes subnacionais devido à falta de dados no período analisado. A técnica escolhida foi a análise do vizinho mais próximo (nearest neighbor analysis). Os resultados da análise permitem concluir que houve avanços, ainda que insuficientes, para uma representação patrimonial fidedigna dos entes públicos subnacionais. Tal situação, consequentemente, afeta a representação do patrimônio governamental nas informações consolidadas sobre o setor público nacional. Percebe-se que não há uma consistência na política contábil adotada ao longo do tempo, em matéria de depreciação.

Palavras-chave: Depreciação, Entes Subnacionais, Patrimônio Público.

\section{Abstract:}

The objective of this paper was to compare the effects of the recognition of depreciation in the Brazilian subnational entities in the period between 2003 and 2014. Initially, we sought to collect data related to the variation of accumulated depreciation, property, plant and equipment, and depreciation expenses of all subnational entities (Brazilian States and the Federal District, more specifically), in the database of FINBRA - Finanças do Brasil. The final sample consisted of thirteen subnational entities due to the lack of data in the analyzed period. The technique chosen was the nearest neighbor analysis. The results of the analysis allow to conclude that there have been insufficient advances for a reliable equity representation of subnational public entities. This situation, consequently, affects the representation of the governmental equity in the consolidated information on the Brazilian national public sector. There is no consistency in the accounting policy adopted over time, in terms of depreciation.

KEYWORDS: Depreciation, Subnational entities, Public Equity.

\section{Resumen:}

El objetivo de este artículo fue comparar los efectos del reconocimiento de la depreciación en los entes subnacionales brasileños, en el período entre 2003 y 2014. Así, inicialmente, se buscó recolectar datos relacionados con la variación de la depreciación, del inmovilizado y de la variación patrimonial diminutiva de todos los Estados y el Distrito Federal brasileños, más específicamente, en la base de datos del FINBRA - Finanzas de Brasil. La muestra final es compuesta por trece entes subnacionales por falta de datos en el período analisado. La técnica elegida fue el análisis del vecino más cercano (vecino más cercano). Los resultados del análisis permiten concluir que hubo avances, ahún que insuficientes para una representación patrimonial fidedigna de los entes públicos subnacionales. Tal situación, consecuentemente, afecta la representación del patrimonio gubernamental en las informaciones consolidadas sobre el sector público nacional. Se percibe que no hay una consistencia en la política contable adoptada a lo largo del tiempo, en materia de depreciación.

Palabras clave: Depreciación, Entes Subnacionales, Patrimonio Público. 


\section{INTRODUÇÃO}

No Brasil, o controle dos bens públicos vem sendo negligenciado ao longo do tempo. Em todo o texto da Lei no 4.320/1964, há uma breve e única menção sobre a depreciação no título que trata das autarquias, das empresas públicas e das entidades paraestatais, onde é explicitado que as "previsões para depreciação serão computadas para efeito de apuração do saldo líquido das mencionadas entidades” (Brasil, 1964). Observa-se que não houve uma clara definição do que seria a depreciação, como ocorreu na Lei no 6.404/1976 e que não há uma vedação para que as entidades da administração direta adotassem tal prática.

Conforme afirma Slomski (2013), a depreciação foi relegada a segundo plano por não ser obrigatório para a administração direta a fazer seu registro e evidenciação. Além disto, complementa-se esta afirmação com o tratamento que foi dado à depreciação na Lei no 6.404/1976, aplicável às sociedades anônimas, na qual houve, além de clara conceituação do fenômeno depreciação, a exigência de divulgação dos critérios utilizados (Brasil, 1976).

Desde 2008 vem sendo implantadas as Normas Brasileiras de Contabilidade Técnicas do Setor Público (NBC TSP), em uma parceria entre o Conselho Federal de Contabilidade (CFC) e a Secretaria do Tesouro Nacional (STN). Outro fruto dessa parceria foi a criação em 2011 do Grupo Técnico de Padronização de Procedimentos Contábeis (GTCON) pela Portaria no 109 (e em 2017, foi reformulado pela Portaria n 767 passando a ser denominado Câmara Técnica de Normas Contábeis e de Demonstrativos Fiscais da Federação - CTCONF). Uma das atribuições do CTCONF é analisar e elaborar diagnósticos visando à padronização de procedimentos contábeis em todos os entes da federação.

Dentre as normas editadas, foi emitida a NBC T 16.9, que trata de critérios e procedimentos para o registro contábil da depreciação, da amortização e da exaustão no setor público. Portanto, os entes públicos estão obrigados a reconhecer a depreciação em seus demonstrativos contábeis a partir de 2011. Em 2017, foi emitida a NBC TSP 07 - Ativo Imobilizado, que estabelece a nova padronização para o registro da depreciação, da amortização e da exaustão, a partir de 2019.

Segundo Silva, Costa, Boente e Batista (2011), o reconhecimento da depreciação no setor público vem dar suporte a transição para o regime de competência que visa evidenciar o patrimônio público mais próximo da realidade. E ainda, o regime de competência é considerado mais completo pois, além de incorporar as funções do regime de caixa, também acrescenta diversas informações que possibilita análises financeiras, orçamentárias, patrimoniais e de custos (Borges, Poueri, Cardoso, \& Aquino, 2010).

Cabe salientar ainda que a não contabilização da depreciação dos bens públicos vai de contra a transparência pública, pois não reflete o real valor do patrimônio público (Graciliano \& Fialho, 2013).

Diante do exposto, este artigo tem por objetivo comparar os efeitos do reconhecimento da depreciação nos entes subnacionais brasileiros, no período entre 2003 e 2014. Essa análise é importante para traçar um diagnóstico sobre a implementação da depreciação que passou a ser obrigatória a partir de 2011. Cabe ressaltar que vários estados já reconheciam a depreciação de parte de seu imobilizado antes do exercício de 2011.

Alguns estudos relacionados ao tema já foram realizados (Alves \& Roncalio, 2012, Arruda, Paiva \& Paulo, 2012, Dantas et al., 2012, Borghetti et al., 2012, Gomes, 2014), mas não analisaram o período de 2003 a 2014 e em que os estados analisados já realizavam a depreciação desde então, sendo esta uma das contribuições deste artigo.

De forma resumida, após consulta aos estudos realizados (Alves \& Roncalio, 2012, Arruda, Paiva \& Paulo, 2012, Dantas et al., 2012, Borghetti et al., 2012, Gomes, 2014), pode-se afirmar que, na atual situação, os estudos realizados ainda não permitem o conhecimento do exato grau da implementação da prática de depreciação pelos entes públicos brasileiros.

Diante do exposto, há muito ainda a se pesquisar e este artigo contribui para diminuir esta lacuna e despertar a importância de uma política contábil consistente ao longo do tempo. 
O presente estudo compreende, também, uma oportunidade para discutir a implementação de procedimentos oriundos da adoção do regime de competência pelas entidades governamentais brasileiras. Em pleno processo de convergência aos padrões internacionais, pesquisas sobre tais fenômenos são capazes de contribuir para uma melhor compreensão dos procedimentos implementados, bem como para a identificação de problemas, fraquezas e oportunidades do processo de convergência.

\section{FUNDAMENTAÇÃO TEÓRICA}

\subsection{Evolução das normas contábeis e a aplicação da depreciação no setor público}

Ao final da década de 1990 iniciou-se um movimento mundial para a adoção de padrões internacionais de contabilidade no setor público, liderado pela International Federation of Accountants (IFAC), que é a entidade responsável pela divulgação das International Public Sector Accounting Standards (IPSAS), emitidas pelo International Public Sector Accounting Standards Board (IPSASB) (Oulasvirta, 2014).

A convergência tem por objetivo melhorar a qualidade da informação contábil. Ball e Pflugrath, (2012) ressaltam que governos com práticas contábeis precárias são incapazes de tomar decisões quanto a distribuição dos escassos recursos públicos de forma eficaz.

Desde 2008, o Brasil vem buscando a implementação das normas internacionais de contabilidade para os setores público e privado. No setor privado, esta adoção foi concluída em 2010. Já no setor público, o que houve foi um discurso que seriam adotadas as IPSAS, entretanto, essa convergência foi mais retórica do que real.

Na prática, o que ocorreu no setor público foi a edição de onze normas denominadas NBC TSP (o que não deixa de ser um grande avanço), mas não há de se confundir com a convergência às normas internacionais de contabilidade aplicadas ao setor público.

Em 2015, o CFC e a STN reativaram a parceria para iniciar uma nova fase do processo de convergência das normas brasileiras do setor público para o padrão internacional. Nessa nova fase, há a esperança de que ocorra em um futuro breve uma convergência de fato, havendo a adoção da maioria dos conceitos contidos nas IPSAS. Um exemplo disto foi a publicação da Estrutura Conceitual no ano de 2016 (Conselho Federal de Contabilidade, 2016).

De modo resumido, na Figura 1, apresenta-se a evolução do processo de convergência ao padrão internacional no modelo contábil do setor público brasileiro:

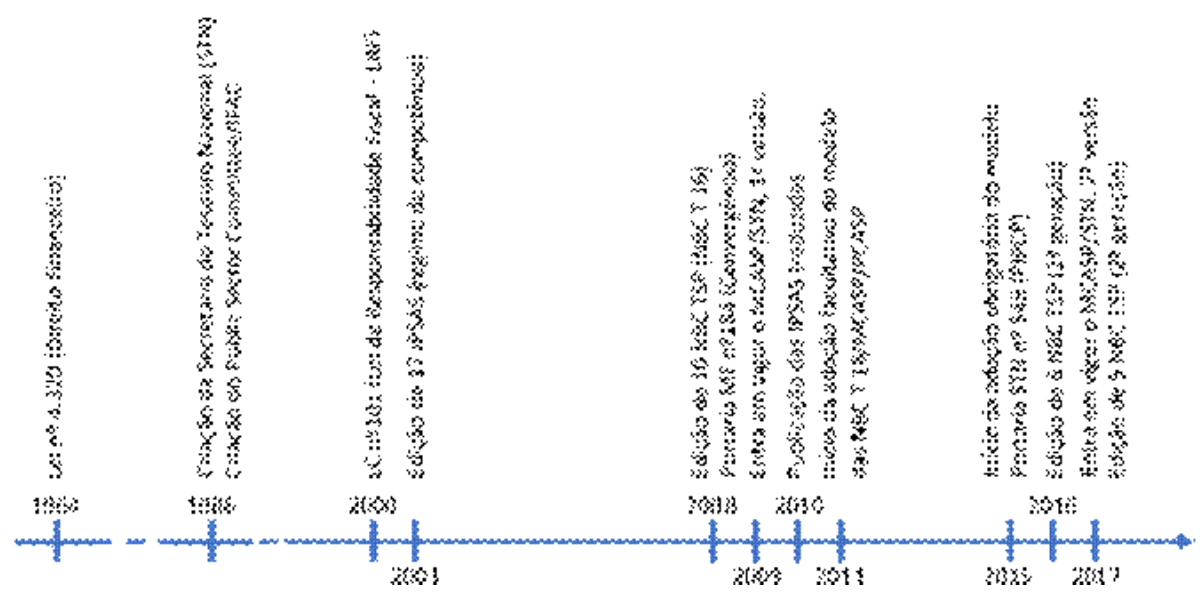

Figura 1 - Evolução do processo de convergência das normas de contabilidade aplicadas ao setor público para o padrão internacional (IPSAS)

Fonte: Adaptado de Secretaria do Tesouro Nacional (2013) 
Quanto à depreciação, de acordo com a norma NBC TSP 07 (Conselho Federal de Contabilidade, 2017), ela compreende a alocação sistemática do custo do ativo ou outro montante que substitua seu custo, menos seu valor residual. A depreciação é o montante de benefícios econômicos futuros consumidos da vida útil de um determinado ativo.

Trata-se de uma queda do potencial de geração de serviços por ativos de longa duração, devido a fatores como: (a) deterioração física; (b) desgastes com uso e (c) obsolescência (Bezerra Filho, 2015).

Esse reconhecimento traz impactos que podem ser significativos no resultado patrimonial dos entes públicos, tendo em vista que a despesa com depreciação os afeta de forma negativa. Por isso, quando não reconhecida no resultado, a situação patrimonial não representa a realidade econômica do ente público.

Conforme destacam Lopes e Martins (2007, p. 72) "é nos accruals que reside o conteúdo informativo da contabilidade". Portanto, além de reconhecer a depreciação nos demonstrativos contábeis, evidenciar a taxa e o método de depreciação, por exemplo, é de fundamental importância para a tomada de decisão e a transparência.

Baptista (2009) destaca que a depreciação é um dos instrumentos potenciais de manipulação pois, se não mensurada de acordo com a vida útil econômica, a despesa com depreciação pode afetar o resultado do exercício. Analisando do lado público, se o ente não mensurar adequadamente o desgaste do imobilizado ou a perda de seu valor econômico, o resultado patrimonial não estará representando a realidade.

Silva (2009) defende que a obrigatoriedade de contabilização das despesas de depreciação contribuirá para uma gestão patrimonial mais eficiente.

No relatório e parecer prévio sobre as contas do governo federal de 2014 emitido pelo Tribunal de Contas da União, a Corte de Contas destacou que "a falta de confiabilidade nos valores registrados de depreciação de bens móveis e imóveis da União compromete a avaliação do patrimônio da União, provocando distorções no Balanço Patrimonial difíceis de quantificar, além de prejuízo no controle dos imóveis pela administração pública" (Tribunal de Contas da União, 2016, p. 440).

E ainda verificou-se que, na União, o valor da depreciação está muito aquém do esperado (2\%), quando comparado aos índices de outros entes governamentais de outros países, em que a depreciação chega a ser superior a $50 \%$ do valor do imobilizado, como os Estados Unidos (52,79\%), União Europeia (42,6\%) e Argentina (30,37\%) (Tribunal de Contas da União, 2016).

É bom ressaltar a existência de vários métodos de depreciação: (a) método das quotas constantes; (b) das somas dos dígitos dos anos e (c) das unidades produzidas. Cada método pode levar a valores diferentes e cada ente vai escolher sua política contábil e determinar a vida útil econômica de cada bem. Entretanto, esse tema não é foco deste artigo.

De acordo com Graciliano e Fialho (2013), os relatórios contábeis são uma forma de divulgação das informações aos cidadãos, sendo o profissional contábil uma peça fundamental na preparação e evidenciação das informações contábeis. Nesse mesmo sentido, a NBC TSP Estrutura Conceitual (Conselho Federal de Contabilidade, 2016) descreve que os relatórios contábeis devem fornecer informações com os objetivos de subsidiar os processos decisórios dos usuários e de prestar contas do uso dos recursos públicos.

A NBC TSP Estrutura Conceitual (Conselho Federal de Contabilidade, 2016) complementa que a omissão de algumas informações pode afetar a representação fidedigna dos fenômenos econômicos. A depreciação é um exemplo de fenômeno (consumo de benefícios econômicos), logo, de acordo com esse raciocínio, a prática e a divulgação das informações relacionadas com a depreciação contribuem para uma representação fidedigna do patrimônio público. 


\subsection{Mudança no Regime Contábil}

As alterações ocorridas no modelo contábil governamental brasileiro estão inseridas em um contexto global. Estas alterações decorrem da mudança do regime de caixa para o regime de competência no modelo contábil das entidades públicas.

O debate sobre o uso do regime de competência vem ganhando corpo ao longo das últimas três décadas (Carlin, 2005; Wynne, 2007). Nova Zelândia e Austrália são exemplos de países que já concluíram, há quase duas décadas, a adoção do regime de competência pelo setor público (Carlin, 2005). Wynne (2007) destaca que a primeira adoção do regime de competência, no âmbito de um governo nacional, ocorreu no Chile na década de 1970, durante o governo do general Pinochet.

$\mathrm{Na}$ década de 2000, ocorreu um aumento acentuado na adoção do regime de competência pelos países. Wynne (2007) destaca que, em 2003, metade dos países da Organização para a Cooperação e Desenvolvimento Econômico (OCDE) já tinha adotado o regime de competência para as contas do governo central.

No regime de caixa, o reconhecimento de receitas e despesas está atrelado à movimentação do caixa e equivalentes. No regime de competência, por sua vez, tal reconhecimento está vinculado à movimentação de benefícios econômicos, independente da alteração do caixa e seus equivalentes. A principal diferença entre esses regimes, segundo Martins (1999), é que o regime de competência propicia uma realocação dos fluxos de caixa, do período da efetiva entrada ou saída para o momento em que ocorreu a fruição dos benefícios econômicos.

Hyndman e Connolly (2011) descrevem que a mudança do regime de caixa para o de competência é vista no setor público como um aspecto importante da agenda da New Public Managment. A ideia é que as entidades públicas se tornem mais empresariais e focadas em obter melhores desempenhos.

Os defensores da adoção do regime de competência, segundo Hyndman e Connolly (2011), argumentam que esse regime fornece informações mais apropriadas aos gestores públicos, o que tornaria o processo decisório mais eficiente e eficaz no setor público.

De acordo com Suzart e Zuccolotto (2013), o modelo contábil governamental das entidades públicas brasileiras "encontra-se em processo de convergência para o regime de competência". Os autores destacam que as NBC TSP trouxeram, dentre outras novidades para o modelo contábil governamental, a adoção do regime de competência. Além disso, descrevem que o modelo anterior às NBC TSP, era o regime de caixa modificado, ou seja, as receitas e despesas eram reconhecidas, essencialmente, pela movimentação do caixa, porém, havia o reconhecimento de alguns ativos e passivos pela ótica do regime de competência.

Diante deste contexto de adoção do regime de competência pelas entidades públicas brasileiras é que a temática da depreciação ganha relevância. Conforme ressaltado, no modelo contábil anterior à adoção das NBC TSP, o reconhecimento de um imobilizado impactava totalmente o exercício em que era adquirido (no modelo orçamentário brasileiro, a aquisição de um bem representa uma despesa de capital). Todavia, a Lei $\mathrm{n}^{\circ} 4.320$ (Brasil, 1964) obriga que os entes públicos mantenham, em sua contabilidade, "registros sintéticos dos bens móveis e imóveis".

Observa-se que, no modelo anterior, o papel da depreciação não era claro. Em primeiro lugar, não havia a obrigação expressamente definida para a administração direta. Em segundo, na lógica de caixa, a aquisição do bem já havia impactado o resultado em valor integral ao da aquisição. Por último, não havia preocupação com a análise dos fluxos de benefícios econômicos mas tão-somente, da manutenção dos valores de bens móveis e imóveis, na grande maioria das vezes, a custo histórico.

A adoção do regime de competência modificou esta situação. A aquisição de um imobilizado deixa de representar uma despesa (como não houve mudança da Lei n ${ }^{\circ} .320 / 1964$ do ponto de vista orçamentário, continua sendo uma despesa de capital). Deste modo, a depreciação passou a ser o modo de representar o impacto no patrimônio pela fruição de benefícios econômicos oriundos do uso do imobilizado. 
O que antes impactava um único exercício, sob a ótica do regime de caixa, passou a seguir a lógica de fruição de benefícios econômicos, visto que os bens imobilizados costumam ser utilizados em mais de um exercício. De acordo com Robinson (1998), a adoção do regime de competência resulta em melhorias para a mensuração de custos para o setor público pois, com a adoção da prática de depreciação, há uma melhor avaliação dos ativos e melhor alocação da despesa.

\section{METODOLOGIA}

Com o objetivo de comparar os efeitos do reconhecimento da depreciação nos entes subnacionais brasileiros, no período entre 2003 e 2014, o primeiro passo foi coletar os dados. Foram consultadas as bases de dados do FINBRA - Finanças do Brasil, do Sistema de Coleta de Dados Contábeis dos Entes da Federação (SISTN) e, por último, os sites de cada ente estadual da federação para complementar as informações.

A amostra analisada ficou composta por 13 unidades federativas brasileiras: (a) Acre, (b) Bahia, (c) Distrito Federal, (d) Maranhão, (e) Minas Gerais, (f) Pará, (g) Paraná, (h) Pernambuco, (i) Rio de Janeiro, (j) Rio Grande do Norte, (k) Santa Catarina, (l) São Paulo e (n) Sergipe. Os dados compreendem o período entre 2003 e 2014.

Catorze estados foram retirados da análise por falta de dados. Os Estados que não apresentaram depreciação em nenhum dos anos pesquisados foram: (a) Amapá, (b) Goiás, (c) Paraíba, (d) Piauí e (e) Rondônia. Os nove restantes reconheceram a depreciação, mas não em todos os períodos analisados, ou seja, entre 2003 e 2014: (a) Alagoas de 2009 a 2014, (b) Amazonas de 2010 a 2014, (c) Ceará de 2003 a 2012, (d) Espírito Santo de 2005 a 2014, (e) Mato Grosso do Sul de 2003 a 2010 e 2014, (f) Rio Grande do Sul de 2008 a 2014, (g) Roraima de 2010 a 2014, (h) Tocantins de 2012 a 2014 e (i) o Estado do Mato Grosso somente em 2013.

A partir das informações obtidas, foram calculadas três variáveis que visam mensurar o efeito do reconhecimento da depreciação nas demonstrações contábeis evidenciadas pelos governos subnacionais. As variáveis foram as seguintes:

Variação da depreciação acumulada: $\Delta$ dep $=($ depreciação acumulada $\mathrm{t}-$ depreciação acumulada $\mathrm{t}-1) /$ depreciação acumulada t-1 (1)

Variação do imobilizado: $\Delta$ imo $=($ imobilizado $\mathrm{t}-$ imobilizado $\mathrm{t}-1) /$ imobilizado $\mathrm{t}-1$ (2)

Variação do resultado patrimonial: $\Delta \mathrm{res}=($ resultado patrimonial $\mathrm{t}-$ resultado patrimonial $\mathrm{t}-1) /$ resultado patrimonial $\mathrm{t}-1(3)$

Considerando que o período analisado abrange doze exercícios, após o cálculo das variáveis anteriormente descritas, foram obtidas as médias aritméticas para cada uma das treze unidades federativas brasileiras que compuseram a amostra.

Em relação ao registro e à evidenciação da depreciação, foram observados os conceitos descritos na NBC T 16.9 (Conselho Federal de Contabilidade, 2008). No período analisado era a norma que estava vigente, visto que a NBC TSP 07 (Conselho Federal de Contabilidade, 2017) entrará em vigor no exercício de 2019.

A técnica escolhida foi a análise do vizinho mais próximo (nearest neighbor analysis - NNA). A NNA foi desenvolvida por Clark e Evans (1954) e é uma técnica útil para comparação de distância entre os pontos mais próximos e as que seriam esperadas a partir do comportamento dos dados analisados. Além disso, essa técnica permite a organização dos entes analisados de acordo com características semelhantes e dissemelhantes. Aqueles que apresentaram menores distâncias entre si apresentariam efeitos semelhantes e vice-versa. A reunião de entes parecidos propicia um ganho na análise da amostra, uma vez que evita a repetição de constatações para entes que apresentaram efeitos semelhantes.

De acordo com Cressie (2015), a NNA tem sido utilizada para as mais diversas finalidades. No caso da presente pesquisa, a técnica foi escolhida por permitir a identificação das igualdades e diferenças entre 
os entes subnacionais brasileiros em relação ao efeito do reconhecimento da depreciação. A NNA a partir das variáveis anteriormente descritas, permite a organização visual dos entes subnacionais deixando mais próximos, aqueles que, em tese, estão em situação mais parecida.

Na NNA foi empregada a distância euclidiana como medida principal e foram escolhidos três vizinhos como referência para a distribuição gráfica em três dimensões. As variáveis originais foram normalizadas para a aplicação da técnica, que foi realizada com o apoio do aplicativo SPSS ${ }^{\bullet}$, versão 23.

\section{ANÁLISE DOS RESULTADOS}

A técnica utilizada para análise, a NNA, não faz nenhuma exigência sobre a distribuição das variáveis. Entretanto, entender o comportamento das variáveis analisadas auxilia na melhor compreensão do fenômeno estudado. Desse modo, são apresentadas as estatísticas descritivas no Quadro 1.

Quadro 1 - Estatísticas descritivas.

\begin{tabular}{|l|l|l|l|}
\hline Estatística & $\Delta$ dep & $\Delta$ imo & $\Delta$ res \\
\hline Média & $14,71 \%$ & $14,28 \%$ & $-16,70 \%$ \\
Desvio- & $15,81 \%$ & $7,84 \%$ & $145,10 \%$ \\
padrão & & & \\
Mínimo & $-2,77 \%$ & $5,42 \%$ & $-430,27 \%$ \\
Máximo & $52,90 \%$ & $28,43 \%$ & $264,74 \%$ \\
Assimetria & 1,067 & 0,553 & $-1,374$ \\
Curtose & 3,607 & 1,952 & 7,236 \\
\hline
\end{tabular}

Fonte: Dados da Pesquisa (2016).

Em relação à variação da depreciação ( $\Delta$ dep), verificou-se uma distribuição assimétrica positiva, significando que a maioria dos valores se encontram acima da média e, consequentemente, indica a existência de uma variação do comportamento desta variável ao longo do tempo e entre os indivíduos analisados. Com um valor mínimo negativo, observa-se que houve casos em que o valor da depreciação acumulada reduziu de um exercício para o outro.

Em relação à variação do imobilizado ( $\Delta$ imo), notou-se que a variável possui uma distribuição achatada e levemente assimétrica positivamente. Na prática, significa que há pouca dispersão de valores e que a maioria desses valores são superiores à média. Em todos os casos sempre houve incremento no valor do imobilizado dos entes subnacionais, ao longo do período em análise.

Em relação à última variável, a variação do resultado patrimonial ( $\Delta$ res), verificou-se que esta possui uma distribuição afunilada e assimétrica negativamente. As estatísticas descritas apontam para uma grande dispersão dos dados analisados e que ocorreu uma grande variação entre os indivíduos no período em análise.

A seguir, passa-se a análise gráfica do espaço preditor. Na Figura 2 é apresentada a distribuição gráfica obtida com a aplicação da NNA. 


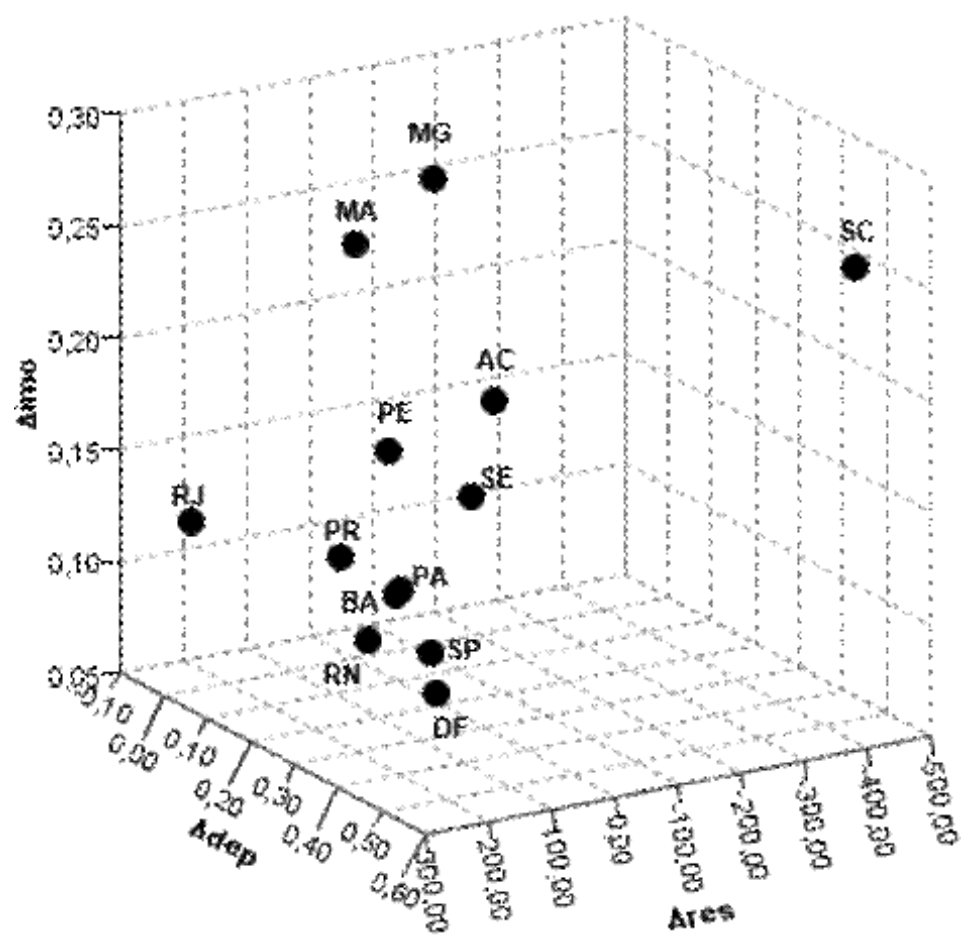

Figura 2 - Espaço preditor.

Visualmente, percebe-se que Santa Catarina se destaca das demais unidades federativas, com uma distância média de 2,326. Outras unidades federativas que também se diferenciam dos demais são Minas Gerais e Maranhão, com distâncias médias de 1,567 e 1,356, respectivamente. As menores distâncias médias foram apresentadas por Bahia e Pará com 0,881 e 0,888, respectivamente.

Quadro 2 - Matriz de distâncias obtidas com NNA.

\begin{tabular}{|c|c|c|c|c|c|c|c|c|c|c|c|c|c|}
\hline & $\mathrm{AC}$ & $B A$ & $\mathrm{DF}$ & MA & MG & $\mathrm{PA}$ & $\mathrm{PE}$ & PR & RJ & RN & SC & $\mathrm{SE}$ & SP \\
\hline $\mathrm{AC}$ & - & & & & & & & & & & & & \\
\hline $\mathrm{BA}$ & 1,228 & - & & & & & & & & & & & \\
\hline $\mathrm{DF}$ & 1,357 & 0,483 & - & & & & & & & & & & \\
\hline MA & 1,243 & 1,308 & 1,722 & - & & & & & & & & & \\
\hline MG & 0,903 & 1,695 & 2,000 & 0,807 & - & & & & & & & & \\
\hline PA & 1,258 & 0,031 & 0,441 & 1,323 & 1,720 & - & & & & & & & \\
\hline PE & 0,996 & 0,526 & 0,935 & 0,788 & 1,219 & 0,544 & - & & & & & & \\
\hline PR & 1,580 & 0,483 & 0,849 & 1,238 & 1,829 & 0,463 & 0,632 & - & & & & & \\
\hline RJ & 1,502 & 0,891 & 1,183 & 1,220 & 1,681 & 0,886 & 0,833 & 0,832 & - & & & & \\
\hline RN & 1,713 & 0,495 & 0,684 & 1,550 & 2,086 & 0,466 & 0,868 & 0,336 & 1,035 & - & & & \\
\hline SC & 1,523 & 2,423 & 2,469 & 2,284 & 1,768 & 2,452 & 2,231 & 2,747 & 2,951 & 2,825 & - & & \\
\hline SE & 0,474 & 0,775 & 0,886 & 1,231 & 1,201 & 0,806 & 0,690 & 1,179 & 1,218 & 1,267 & 1,800 & - & \\
\hline SP & 1,320 & 0,270 & 0,191 & 1,563 & 1,893 & 0,267 & 0,777 & 0,675 & 1,035 & 0,543 & 2,441 & 0,847 & - \\
\hline
\end{tabular}

Fonte: Dados da Pesquisa (2016).

Em relação a Santa Catarina, durante o período analisado, a variação média anual da depreciação acumulada foi de 52\%, aproximadamente. O crescimento médio anual do imobilizado foi por volta de 26\%. Nota-se, assim, que ao longo do período entre 2003 a 2014, Santa Catarina vem reconhecendo gradativamente a depreciação do seu imobilizado. A variação da depreciação acumulada superior à variação do imobilizado sugere uma evidência da aplicação de forma gradual da técnica de depreciação. 
Outro aspecto que reforça a evidência anteriormente apresentada é a forte variação do resultado patrimonial de Santa Catarina, ao longo do período analisado. Tal variação indica que mudanças ocorreram na forma de mensuração e de reconhecimento dos ativos e passivos da unidade federativa.

Rio de Janeiro e Rio Grande do Norte são as unidades federativas com maiores distâncias em relação à Santa Catarina, conforme os valores apresentados na matriz de distâncias.

A distância entre o Rio de Janeiro e Santa Catarina foi de 2,951. No Rio de Janeiro, a variação média anual da depreciação acumulada foi de $1 \%$, enquanto a variação média anual do imobilizado foi de $12 \%$, ambas indicando crescimentos nominais. Observa-se que apesar do crescimento do imobilizado, a depreciação acumulada cresceu em um ritmo muito menor, o que é um indicativo de instabilidade da prática (mudanças de critérios, de taxas ou de bases de cálculo, por exemplo) durante os anos de 2003 a 2014. Como exemplo desse fato, destaca-se que houve redução do valor da depreciação acumulada em cerca de $47 \%$, enquanto houve um crescimento no imobilizado de cerca de $63 \%$.

A distância entre o Rio Grande do Norte e Santa Catarina foi de 2,825. No Rio Grande do Norte a depreciação acumulada é mesma durante todo o período analisado, ou seja, não houve variação. Percebese que não há a prática da depreciação naquela unidade federativa durante os anos de 2003 a 2014 . O imobilizado apresentou um crescimento de 5,7\% no período analisado.

Dentre as unidades federativas com menor distância entre si, destacam-se os seguintes pares: (a) Bahia e Pará (distância de 0,031) e (b) São Paulo e Distrito Federal (distância de 0,191). Na Bahia e no Pará, o comportamento das variações da depreciação acumulada e do imobilizado são bastante semelhantes. $\mathrm{Na}$ Bahia, a variação média anual da depreciação acumulada foi de $11 \%$, aproximadamente, enquanto a variação média anual do imobilizado foi de cerca de $9 \%$. No Pará, estes valores foram de $10 \%$ e $9 \%$, respectivamente, no período analisado. A partir de tais evidências, nota-se que, em ambas as unidades federativas, a prática do registro da depreciação ocorre e que não houve mudanças significativas ao longo dos anos de 2003 a 2014. Todavia, a prática no Pará parece ter sido iniciada mais recentemente do que na Bahia. No Pará, a depreciação acumulada representa $1,1 \%$ do total do imobilizado em 2014. Na Bahia, esse montante era de 30,7\%, no mesmo período.

Com o estado de São Paulo e com o Distrito Federal ocorre algo semelhante. Em São Paulo a variação média anual da depreciação acumulada foi de $19 \%$, aproximadamente, enquanto que a variação média anual do imobilizado foi de cerca de 5\%. No Distrito Federal, estes valores foram de 15\% e 7\%, respectivamente. Observa-se que, nestas unidades federativas, a variação da depreciação acumulada é superior à variação do imobilizado. Isso evidencia que a prática de depreciação vem sendo implementada pelas unidades e que a cada exercício são acrescidos bens que, até então, não compunham a base de cálculo para a depreciação.

De igual modo ao par anterior, há indícios que a prática no Distrito Federal foi iniciada antes do que em São Paulo. A depreciação acumulada representa 11,7\% do total do imobilizado do Distrito Federal, enquanto em São Paulo o valor era de 5,6\%, no exercício de 2014.

Minas Gerais é a segunda unidade federativa que mais se distancia, em média, das demais unidades, conforme foi explicitado anteriormente. A variação média anual da depreciação acumulada apresenta um crescimento de $18 \%$ no período entre 2003 a 2014. Contudo, esse comportamento não foi uniforme durante o período analisado. Foram identificadas duas grandes mudanças comportamentais (entre 2010 e 2011 e entre 2013 e 2014), onde houve redução da depreciação acumulada, apesar de não ter havido redução do valor do imobilizado. Durante o período analisado, Minas Gerais apresentou uma variação média anual do imobilizado de cerca de $28 \%$, em uma tendência de crescimento nominal.

A partir dos indícios anteriormente apresentados, observa-se que, apesar de a prática de depreciação estar implementada na unidade federativa, tem havido mudanças nos critérios utilizados pela unidade. As reduções identificadas são indícios de que a prática vem sendo revista ao longo do período analisado.

Essa observação é reforçada pela forte variação e ausência de tendência do resultado patrimonial da unidade federativa, ao longo do período de 2003 a 2014, com destaque para o exercício de 2009, quando o resultado 
patrimonial de Minas Gerais foi negativo em $\mathrm{R} \$ 19$ bilhões. A forte variação do resultado patrimonial é um indício de alteração na forma de mensuração de ativos e passivos, o que pode justificar o comportamento da depreciação acumulada.

O Maranhão foi a unidade federativa que apresentou a terceira maior distância média em relação às demais unidades, cerca de 1,356.

A variação média anual da depreciação acumulada foi de $1 \%$, com tendência negativa para esta unidade federativa, ao longo do período analisado. Por sua vez, a variação média anual do imobilizado foi de $23 \%$, com tendência positiva, durante o mesmo período.

Da mesma forma que em Minas Gerais, no Maranhão foram observadas reduções na depreciação acumulada em dois períodos: (a) entre 2005 e 2006 e (b) entre 2008 e 2009. Apenas no segundo período a redução da depreciação acumulada foi acompanhada de redução do imobilizado. Apesar de reduções menos bruscas do que as observadas em Minas Gerais, pode se afirmar que os critérios para o cálculo da depreciação também foram revistos pelo Maranhão, durante os anos de 2003 a 2014.

No quadro 3, apresenta-se o comportamento do Acre, do Paraná, de Pernambuco e de Sergipe em relação às variáveis em análise.

\section{QUADRO 3 - VARIAÇõES DAS DEMAIS UNIDADES FEDERATIVAS ANALISADAS.}

\begin{tabular}{|l|l|l|l|}
\hline Unidade & $\Delta$ dep & $\Delta$ imo & $\Delta$ res \\
Federativa & & & \\
\hline Acre & $32,9 \%$ & $19,9 \%$ & $336,9 \%$ \\
Paraná & $-2,8 \%$ & $9,3 \%$ & $-33,4 \%$ \\
Pernambuco & $7,7 \%$ & $15,1 \%$ & $-321,4 \%$ \\
Sergipe & $26,9 \%$ & $15,1 \%$ & $-100,0 \%$ \\
\hline
\end{tabular}

Fonte: Dados da Pesquisa (2016).

As quatro unidades federativas citadas se apresentam em uma posição intermediária, de acordo com uma análise visual do espaço preditor. Acre e Pernambuco apresentam crescimento médio anual da depreciação acumulada (com exceção do período entre 2003 e 2004, no caso de Pernambuco) de 32,9\% e $7,7 \%$, respectivamente. Todavia, no Acre, a variação da depreciação acumulada foi superior à variação do imobilizado no período analisado, enquanto em Pernambuco ocorreu o contrário.

Nota-se que a prática de depreciação também está implementada nessas unidades federativas, contudo, parece que o processo se encontra mais estável no Acre do que em Pernambuco. Ambas unidades continuam a implementar outras mudanças, conforme foi evidenciado pela variação média anual do resultado patrimonial, demonstrado no quadro anteriormente apresentado.

O Paraná apresenta uma situação ímpar: a depreciação acumulada vem diminuindo ao longo do período analisado (uma redução anual média de $2,8 \%$ ), enquanto houve crescimento do imobilizado no mesmo período (um crescimento anual médio de 9,3\%).

As reduções do valor da depreciação acumulada, para esta unidade federativa, ocorreram entre: (a) 2005 e 2006, (b) 2007 e 2008, (c) 2009 e 2010 e (d) 2011 e 2012. Entre os anos de 2009 e 2010 a redução foi de 58\%. Em relação ao imobilizado, houve redução apenas entre os anos de 2008 e 2009. Tais evidências demonstram que a prática de depreciação tem sido afetada por mudanças nos critérios utilizados no Paraná. Há, portanto, instabilidade de tais critérios, o que conduz a grandes variações no valor apresentado de depreciação acumulada.

Em relação a Sergipe, também, foi identificada uma situação incomum: durante os anos de 2003, 2004, 2008, 2009 e 2010, o valor da depreciação acumulada foi o mesmo. Observa-se uma inconsistência no registro da depreciação nessa unidade federativa. 
A prática de depreciação voltou a ocorrer a partir de 2011 e, desde então, parece estar sendo gradualmente implementada, visto que a variação média anual da depreciação acumulada é muito superior à variação do imobilizado, no período compreendido entre os anos de 2011 e 2014.

No quadro 4, apresenta-se os estágios de implementação do reconhecimento da depreciação nos entes subnacionais brasileiros, no período entre 2003 e 2014.

Quadro 4 - Resumo da prática de reconhecimento da depreciação - Período 2003 a 2014.

\begin{tabular}{|c|c|c|}
\hline Unidade Federativa & $\begin{array}{l}\text { Reconhece } \\
\text { depreciaçầo }\end{array}$ & Estágio de Implementação \\
\hline Acre & $\operatorname{sim}$ & $\begin{array}{l}\text { Gradual intensificação a } \\
\text { partir de } 2007\end{array}$ \\
\hline Bahia & $\operatorname{Sim}$ & $\begin{array}{l}\text { Prática já estável desde } \\
2003\end{array}$ \\
\hline Distrito Federal & $\operatorname{Sim}$ & $\begin{array}{l}\text { Forte intensificação a } \\
\text { partir de } 2003\end{array}$ \\
\hline Maranhão & $\operatorname{Sim}$ & Prática instável \\
\hline Minas Gerais & $\operatorname{Sim}$ & Prática instável \\
\hline Pará & $\operatorname{Sim}$ & $\begin{array}{l}\text { Forte intensificação a } \\
\text { partir de } 2008\end{array}$ \\
\hline Paraná & $\operatorname{Sim}$ & Prática instável \\
\hline Pernambuco & $\operatorname{sim}$ & $\begin{array}{l}\text { Gradual intensificação a } \\
\text { partir de } 2005\end{array}$ \\
\hline Rio de Janeiro & $\operatorname{sim}$ & $\begin{array}{l}\text { Gradual intensificação a } \\
\text { partir de } 2010\end{array}$ \\
\hline $\begin{array}{l}\text { Rio Grande do } \\
\text { Norte }\end{array}$ & Não & Não se aplica \\
\hline Santa Catarina & $\operatorname{Sim}$ & $\begin{array}{l}\text { Forte intensificação a } \\
\text { partir de } 2010\end{array}$ \\
\hline São Paulo & $\operatorname{sim}$ & $\begin{array}{l}\text { Gradual intensificação a } \\
\text { partir de } 2005\end{array}$ \\
\hline Sergipe & $\operatorname{Sim}$ & $\begin{array}{l}\text { Gradual intensificação a } \\
\text { partir de } 2011\end{array}$ \\
\hline
\end{tabular}

Fonte: Dados da Pesquisa (2016).

Conforme demonstrado no quadro 4 há muito a se evoluir na evidenciação da depreciação contábil no setor público e consequentemente de todo o patrimônio público. Como já comentado com dados ineficientes, as tomadas de decisões também não são eficazes.

Também foram analisadas as notas explicativas do exercício dos 13 entes subnacionais, com o objetivo de verificar os critérios de depreciação utilizados. Entretanto, somente os estados do Rio de Janeiro, Pará e Santa Catarina apresentaram explicações mais detalhadas. O Estado do Pará calcula a depreciação pelo método linear de acordo com a vida útil econômica dos bens. Já o Estado de Santa Catarina utiliza o método de quotas constantes e com base na tabela definida pela Secretaria de Estado da Administração, com base na Instrução Normativa da Secretaria da Receita Federal $n^{\circ} 162 / 1998$, portanto, sem utilizar a vida útil econômica como determinado pela NBC T 16.9 (Conselho Federal de Contabilidade, 2008).

Já o estado do Rio de Janeiro não citou o método de depreciação, mas explicitou que utiliza o critério de vida útil econômica e que em 2014 foi publicada a Portaria $\mathrm{n}^{\circ} 179$ que orienta a operacionalização dos procedimentos de depreciação, entretanto este normativo não cita o método a ser utilizada, só informa o valor residual de cada grupo de bens e sua taxa de depreciação.

\section{CONSIDERAÇÕES FINAIS}

A prática da depreciação é uma daquelas que emergiram com a adoção do regime de competência pelas entidades do setor público brasileiro. Desde a edição da NBC T 16.9 até a sua efetiva implementação, ficou 
evidente em diversos trabalhos realizados (Alves \& Roncalio, 2012; Borghetti et al., 2012; Dantas et al., 2012; Gomes, 2014) que não havia uma consolidação desta prática entre os entes subnacionais.

Em uma visão macro, os achados da pesquisa permitem concluir que os entes subnacionais brasileiros estão adotando novas práticas e/ou modificando práticas existentes, utilizando conceitos oriundos do regime de competência e modificando o modelo contábil governamental. É o fenômeno da transição para o regime de competência vivenciados por alguns países, conforme atestaram Carlin (2005), Wynne (2007) e Hyndman e Connolly (2011).

Com uma amostra de quase $50 \%$ dos governos subnacionais brasileiros, no âmbito das unidades federativas, foi demonstrado que a prática ainda é incipiente, mas com alguns entes se esforçando para representar uma demonstração contábil de qualidade. Entretanto, muito se tem a evoluir, sendo necessário que ocorra a adoção de prática contábil consistente ao longo do tempo.

No caso brasileiro, os resultados atestam que a prática de reconhecimento e evidenciação da depreciação foi uma daquelas que foi implementada, mesmo que ainda não tenha-se estabilizado ou seja capaz de gerar informações com mais qualidade. Essa prática é um dos resultados do processo de convergência para o regime de competência, vivenciado pelos entes públicos brasileiros e descrito por Suzart e Zuccolotto (2013).

Santa Catarina foi a unidade federativa que mais se distanciou das demais unidades analisadas. Nesse estado foi identificada forte intensificação da prática de depreciação a partir do ano de 2010. Santa Catarina também foi uma das unidades que apresentaram notas explicativas com detalhes sobre as escolhas contábeis para a implementação dessa prática. Nota-se, assim, um esforço para o aperfeiçoamento das informações contábeis sobre o patrimônio público.

Apesar da evolução apresentada por Santa Catarina, verificou-se, de igual modo a Alves e Roncalio (2012), o uso das taxas de depreciação propostas pela SRFB, desconsiderando, assim, a vida útil dos bens. O uso das taxas propostas pela SRFB desconsidera a fruição dos benefícios econômicos. Tal fato demonstra que a essência do regime de competência, a movimentação de benefícios econômicos, ainda não é o principal critério no momento de definição da política contábil sobre a depreciação.

Além de Santa Catarina, Rio de Janeiro e Pará foram as unidades federativas que apresentaram maiores detalhes da prática de depreciação em suas notas explicativas. O Pará demonstra uma forte intensificação dessa prática desde o ano de 2008. No Rio de Janeiro notou-se um indicativo de instabilidade da depreciação, apesar da gradual intensificação da mesma a partir de 2010.

Outro fato de destaque foi o aumento do número de entes subnacionais que passaram a divulgar informações sobre a depreciação. Gomes (2014) havia identificado que, no ano de 2012, 33\% dos estados (incluindo o Distrito Federal) não divulgavam tal informação. Neste artigo verificou-se que este percentual foi de cerca de 22\%. Amapá, Goiás, Paraíba, Rondônia e Rio Grande do Norte (esse último, apesar de compor a amostra, não alterou o valor da depreciação acumulada durante o período analisado) foram os entes subnacionais que demonstram não ter implementado a prática de depreciação.

A Bahia é a unidade federativa cuja prática de depreciação demonstra uma estabilidade desde 2003. Em 2014, a depreciação acumulada representava 30,7\% do total do imobilizado, naquela unidade. A Bahia apresentou a mais alta taxa em comparação com as demais unidades, bem próxima de governos nacionais que já implementaram tal prática, de acordo com as informações do Tribunal de Contas da União (2016).

Um especial destaque se refere ao ciclo político do setor público brasileiro. Sabe-se que a cada quatro anos pode haver mudança dos gestores, o que pode prejudicar o processo de implementação. Esse fato não foi analisado no presente artigo, mas precisa ser considerado na análise da implementação da prática de depreciação.

Outra limitação da pesquisa se refere aos procedimentos metodológicos escolhidos. As inferências foram decorrentes apenas da aplicação da técnica estatística e da análise das notas explicativas. 
Por fim, diante do cenário exposto, pode-se inferir que houve avanços, mas que estes foram insuficientes para uma representação patrimonial fidedigna dos entes públicos subnacionais e que, posteriormente, reflete no patrimônio público nacional.

\section{REFERÊNCIAS}

Alves, J. L., \& Roncalio, M. P. (2012). Evidenciação patrimonial no estado de Santa Catarina: desafios resultantes da adoção das normas de contabilidade aplicadas ao setor público. Anais do VI Congresso da Associação Nacional de Programas de Pós-graduação em Ciências Contábeis - ANPCONT, Florianópolis, SC, Brasil, 1-15.

Ball, I. \&, Pflugrath, G. (2012). Government accounting - making Enron look good. World Economics, 13(1), 9-26.

Baptista, E. M. (2009). Ganhos em transparência versus novos instrumentos de manipulação: o paradoxo das modificações trazidas pela Lei no 11.638. Revista de Administração de Empresas, 49(2), 234-239.

Borges, T. B., Poueri, M. C., Cardoso, R. L., \& Aquino, A. C. B. (2010). Desmistificação do regime contábil de competência. Revista de Administração Pública - RAP, 44(4), 877-901.

Borghetti, J., Borghetti, J. C., Stein, F. A., Frosi, M., \& Rodrigues, E. B. M. (2012). Impactos do reconhecimento da depreciação no setor público para o patrimônio dos estados brasileiros. Encontro de Administração Pública e Governo - EnAPG 2012, Salvador, BA, Brasil, 1-13.

Brasil. (1964). Lei $\mathrm{n}^{\circ}$ 4.320, de 17 de março de 1964. Recuperado em 13 outubro, 2016, de http:// www.planalto.gov.br/ccivil_03/leis/L4320.htm.

Brasil. (1976). Lei $\mathrm{n}^{\circ}$ 6.404, de 15 de dezembro de 1976. Recuperado em 13 outubro, 2016, de http:// www.planalto.gov.br/ccivil_03/leis/L6404compilada.htm.

Carlin, T. M. (2005). Debating the impact of accrual accounting and reporting in the public sector. Financial Accountability \& Management, 21(3), 309-336.

Clark, P. J., \& Evans, F. C. (1954). Distance to nearest neighbor as a measure of spatial relationships in populations. Ecology, 35(4), 445-453.

Cressie, N. A. (2015). Statistic for spatial data. New York, Wiley.

Conselho Federal de Contabilidade. (2008). Resolução CFC No. 1.136/08. Recuperado em 14 outubro, 2016, de http://www1.cfc.org.br/sisweb/SRE/docs/RES_1136.doc.

Conselho Federal de Contabilidade. (2016). Norma Brasileira de Contabilidade - NBC TSP Estrutura Conceitual. Recuperado em 14 outubro, 2016, de http://www1.cfc.org.br/sisweb/SRE/docs/NBCTSPEC.doc.

Conselho Federal de Contabilidade. (2017). Normas Brasileira de Contabilidade - NBC TSP 07 Ativo Imobilizado. Recuperado em 24 outubro, 2017, de http://cfc.org.br/wp-content/uploads/2016/06/ NBC_TSP_07_v_03_07_00.doc.

Dantas, C. B., Arruda, M. P., Paiva, A. C. N., \& Paulo, E. (2012). Depreciação no Serviço Público: Reconhecimento e Evidenciação nas Demonstrações Contábeis dos Estados e Municípios Brasileiros. Revista de Contabilidade da UFBA, 6(2), 56-65.

Gomes, J. R. (2014). Nova Contabilidade Aplicada ao Setor Público: um estudo sobre o reconhecimento da depreciação na contabilidade dos estados brasileiros. 12 Prêmio Excelência Acadêmica da Fucape. 2014. Recuperado em 10 julho, 2016, de http://www.fucape.br/premio_excelencia_academica/upld/trab/14/74.pdf.

Graciliano, E. A., \& Fialho, W. C. D. (2013). Registro da depreciação na Contabilidade Pública: uma contribuição para o disclosure de Gestão. Pensar Contábil, 15(56), 14-21.

Hyndman, N., \& Connolly, C. (2011). Accruals accounting in the public sector: A road not always taken. Management Accounting Research, 22(1), 36-45.

Lopes, A. B., \& Martins, E. (2007). Teoria da Contabilidade - uma nova abordagem. São Paulo: Atlas, 2007.

Martins, E. (1999). Contabilidade versus fluxo de caixa. Cadernos de Estudos - Fipecafi, 20, 1-10.

Oulasvirta, L. O. (2014). Governmental Financial Accounting and European Harmonisation: Case Study of Finland. Accounting Economic Law, 4(3), 237-263. 
Robinson, M. (1998). Accrual Accounting and the efficiency of the core public sector. Financial Accountability \& Management, 10(3), 354-374.

Silva, L. M. S. (2009). ( $8^{a}$ Ed.). Contabilidade Governamental: um enfoque administrativo da nova contabilidade pública. São Paulo: Ed. Atlas.

Silva, M. C., Costa, G. B., Boente, D. R., \& Batista, E. M. (2011). Depreciação no Setor Público: análises de procedimentos em uma Unidade Gestora. Boletim de Orçamento e Finanças - Governet, 61(73), 418-432.

Secretaria do Tesouro Nacional. (2013). Nova Contabilidade e Gestão Fiscal: Modernização da Gestão Pública. Recuperado em 24 outubro, 2017, de http://www.tesouro.fazenda.gov.br/documents/10180/329483/ PGE_CARTILHA_NovaContabilidade_GestaoFiscal.pdf/92871964-4c76-4d6a-bc11-80eaac9c46cd.

Secretaria do Tesouro Nacional. (2016a). FINBRA - Finanças do Brasil. Recuperado em 30 março, 2016, de https:// siconfi.tesouro.gov.br/siconfi/pages/public/consulta_finbra/finbra_list.jsf.

Secretaria do Tesouro Nacional. (2016b). Sistema de Coleta de Dados Contábeis de Estados e Municípios - SISTN. Recuperado em 08 maio, 2016, de https://www.contaspublicas.caixa.gov.br/sistncon_internet/index.jsp.

Slomski, V. (2013). (3ªd.) Manual de contabilidade pública: de acordo com as normas internacionais de contabilidade aplicadas ao setor público (IPSASB/IFAC/CFC). São Paulo: Atlas.

Suzart, J., \& Zuccolotto, R. (2013). Estamos a caminho da convergência para as IPSAS? Gestor Contábil, 5, 14-15.

Tribunal de Contas da União. (2014). Relatório e Parecer Prévio sobre as Contas do Governo da República 2014. Brasília, TCU. Recuperado em 29 setembro, 2016, de http://portal.tcu.gov.br/tcu/paginas/contas_governo/ contas_2014/index.html.

Wynne, A. (2007). Is the move to accrual based accounting a real priority for public sector accounting? Public Fund Digest, 6(1), 1-30.

\section{BY-NC-ND}

